\title{
$\beta$-type Ti Alloys for Biomedical Applications
}

\author{
Yavuz HI and Yamanoglu R* \\ Department of Metallurgy and Material Engineering, Kocaeli University, Turkey
}

*Corresponding author: Ridvan Yamanoglu, Department of Metallurgy and Material Engineering, Kocaeli University, Umuttepe Campus, 41001 İzmit / Kocaeli, Turkey, Tel: +90262-303-3083; Email: ryamanoglu@kocaeli.edu.tr

\section{Review Article}

Volume 3 Issue 2

Received Date: August 15, 2020

Published Date: September 08, 2020

DOI: $10.23880 /$ aabsc-16000151

\section{Abstract}

In the world market, medical products emerge as a sector that directly concerns people's life quality and related activities. The medical product industry continues to grow rapidly in the world, especially in developed countries in line with the advances in technology, along with the elderly population and welfare level. In this context, biomedical implants constitute an important branch of the medical product industry. Among the materials preferred for implant production, the metallic biomaterials are very popular due to their superior mechanical properties. Ti and Ti alloys, among the metallic biomaterials, draw more attention considerably compared to stainless steel and Co-Cr alloys due to their characteristic features such as high specific strength and superior corrosion resistance, low density and low modulus of elasticity. Although the elastic modulus of titanium and its alloys is low compared to the other metallic biomaterials, it remains higher than bone. $\beta$-type Ti alloys have been developed to prevent the stress shielding effect caused by the elastic modulus mismatch and sterilization of the biomaterials used in the body from toxic alloy elements. In this article, the effect of the use of $\beta$-type Ti alloys, which are extremely prospective materials and open to development, in the body on host organisms, and the efficiency of the developed alloys have been investigated.

Keywords: Biocompatibility; Titanium alloy; Elastic modulus; Phase Structure

\section{Microstructural Characteristics of $\beta$-type Ti Alloys}

The properties of titanium-based materials are strongly influenced by their allotropic transformation. Ti has two major phase structures ( $\alpha$ and $\beta$ ) depending on the temperature under constant pressure. Pure Ti exists in $\alpha$ phase with a hexagonal close-packed (hcp) crystal lattice structure at low temperatures $\left(\mathrm{T}<883^{\circ} \mathrm{C}\right)$ while exists in $\beta$ phase with a body-centred cubic (bcc) structure above $883^{\circ} \mathrm{C}$ [1]. The elements added to Ti change the phase transition temperature between $\alpha+\beta$. For example, elements such as $\mathrm{Al}, \mathrm{O}, \mathrm{N}, \mathrm{C}$ are called $\alpha$-stabilizers because they increase the allotropic transformation temperature and keep the $\alpha$ phase stable in the microstructure, while the elements such as $\mathrm{Nb}$, $\mathrm{Mo}, \mathrm{Ta}, \mathrm{Fe}, \mathrm{Cr}$ are called $\beta$-stabilizers since they decrease the transformation temperature and keep the structure in the $\beta$ phase $[2,3]$. Two types of $\beta$-alloys, namely semi-stable and stable, can be mentioned depending on the amount of $\beta$-stabilizer content in the structure and the cooling rate of the structure from the transformation temperature. The stability of the $\beta$ phase in the microstructure is determined using the Molybdenum Equivalence (Mo-Eq). [Mo- Eq. = $1.0 \mathrm{Mo}+0.67 \mathrm{~V}+0.44 \mathrm{~W}+2.9 \mathrm{Fe}+1.6 \mathrm{Cr}+0.3 \mathrm{Nb}+0.22 \mathrm{Ta}-$ $1.0 \mathrm{Al}$ [ [4]. If the Mo equivalent is 10 or more, it indicates that the structure will completely have the $\beta$ phase at room temperature. Morphology and distribution of the phases in the microstructure are considered to affect the properties of the titanium alloys, therefore it can be predicted that $\beta$-type Ti alloys with a body-centred cubic crystal structure may have different mechanical, chemical, and physical properties in many ways compared to Ti alloys in $\alpha$, near- $\alpha$, and $\alpha+\beta$ phase structure. 


\section{Elastic Modulus of $\beta$-type Ti Alloys}

One of the most common problems with the metallic implant materials used in the body is biomechanical incompatibility due to the elastic modulus mismatch [5]. For this reason, the mechanical relationship between the body and the implant material should be implemented considering the modulus of elasticity. The stresses on the femoral head without any implantation are distributed homogeneously in the bone and transmitted downward. When an implant with a high modulus of elasticity is placed in the same area, the stress on the bone is transmitted to the lower areas through the implant due to the high modulus of elasticity. Therefore, the bone structure around the implant bears less stress than the implant, resulting in bone resorption. As a result of bone resorption, the implant loosens in the area where it is placed, and this phenomenon is called the stress shielding effect $[6,7]$. To prolong the implantation life, it is very important to prevent the above-mentioned biomechanical incompatibility. Although the modulus of elasticity of materials such as pure $\mathrm{Ti}$ and Ti-6Al-4V, which are currently used in the body, are $50 \%$ lower than the $316 \mathrm{~L}$ and Co-Cr alloys, the modulus of elasticity remains higher compared to the bone structure [8]. When the studies in the literature are examined in detail, the order of modulus of elasticity of the phases in Ti-based alloys is as follows: $\omega>\alpha>\alpha^{\prime}>\alpha^{\prime \prime}>\beta$ [9]. Mechanical properties and elastic modulus values of different Ti and its alloys with different phase structures are given in Table 1 . As can be seen in Table 1, keeping the $\beta$ phase in Ti-based biomaterials reduces the modulus of elasticity of titanium alloys and it allows long-term use of the implant by eliminating the stress shielding effect.

\begin{tabular}{|c|c|c|c|c|c|}
\hline Alloy & Yield Strength (MPa) & Ultimate Strength (MPa) & E (GPa) & Phase & Reference \\
\hline Cp-Ti (Grade1) & 170 & 240 & 105 & $\alpha$ & {$[10]$} \\
\hline Cp-Ti (Grade2) & 275 & 345 & 105 & $\alpha$ & {$[10]$} \\
\hline Cp-Ti (Grade3) & 380 & 445 & 105 & $\alpha$ & {$[10]$} \\
\hline Cp-Ti (Grade4) & 480 & 550 & 105 & $\alpha$ & {$[10]$} \\
\hline Ti-6Al-4V & $850-900$ & 970 & 110 & $\alpha+\beta$ & {$[11]$} \\
\hline Ti-5Al-2.5Fe & 820 & 900 & 110 & $\alpha+\beta$ & {$[12]$} \\
\hline Ti-6Al-7Nb & 800 & 900 & 105 & $\alpha+\beta$ & {$[13]$} \\
\hline Ti-3Al-2.5V & 585 & 690 & 100 & $\alpha+\beta$ & {$[12]$} \\
\hline Ti-12Mo-6Zr-2Fe & $1000-1060$ & 1100 & $74-85$ & $\beta$ & {$[14]$} \\
\hline Ti-15Mo-2.8Nb-3Al & 771 & 812 & 82 & $\beta$ & {$[15]$} \\
\hline Ti-13Nb-13Zr & 900 & 1030 & 79 & $\beta$ & {$[11]$} \\
\hline Ti-35Nb-5Ta-7Zr & 793 & 827 & 55 & $\beta$ & {$[12]$} \\
\hline Ti-24Zr-4Nb-8Sn & $563 \pm 38$ & $665 \pm 18$ & 53 & $\beta$ & {$[16]$} \\
\hline Ti-36Nb-2Ta-3Zr-0.30 & $670-1150$ & $835-1180$ & 32 & $\beta$ & {$[15]$} \\
\hline Bone & - & $90-140$ & $10-40$ & - & {$[13]$} \\
\hline
\end{tabular}

Table 1: Mechanical properties and elastic modulus of pure Ti, Ti alloys and bone.

\section{Biocompatibility Properties of $\beta$-type Ti Alloys}

It is an indication of biocompatibility that the implanted biomaterial does not cause any toxic, irritant, inflammatory, allergic, mutagenic, or carcinogenic effects in the host organism. Although stainless steel (316L) and Co-Cr alloys are preferred particularly for hard tissue applications such as hip implants, it has been determined that these materials have properties causing negative effects on the body in terms of biocompatibility due to ion release that have toxic effects on the body [17]. In Figure 1 [18], biocompatibility grades of some elements and alloys are given in detail. At this point, the excellent corrosion resistance of $\mathrm{Ti}$ and $\mathrm{Ti}$ alloys due to the stable surface oxide film and its superior biocompatibility properties in soft and hard tissue applications makes these $\beta$ alloys suitable for use as biomaterials. Although Ti-6Al-4V alloy with $\alpha+\beta$ phase structure is a widely preferred implant composition, the studies in the literature have indicated that vanadium (V) ions cause the toxic effect on the body by altering the kinetics of the enzyme activity associated with inflammatory response cells $[19,20]$. Similarly, Al ions have been found to trigger Alzheimer's disease in the host organism [21]. 


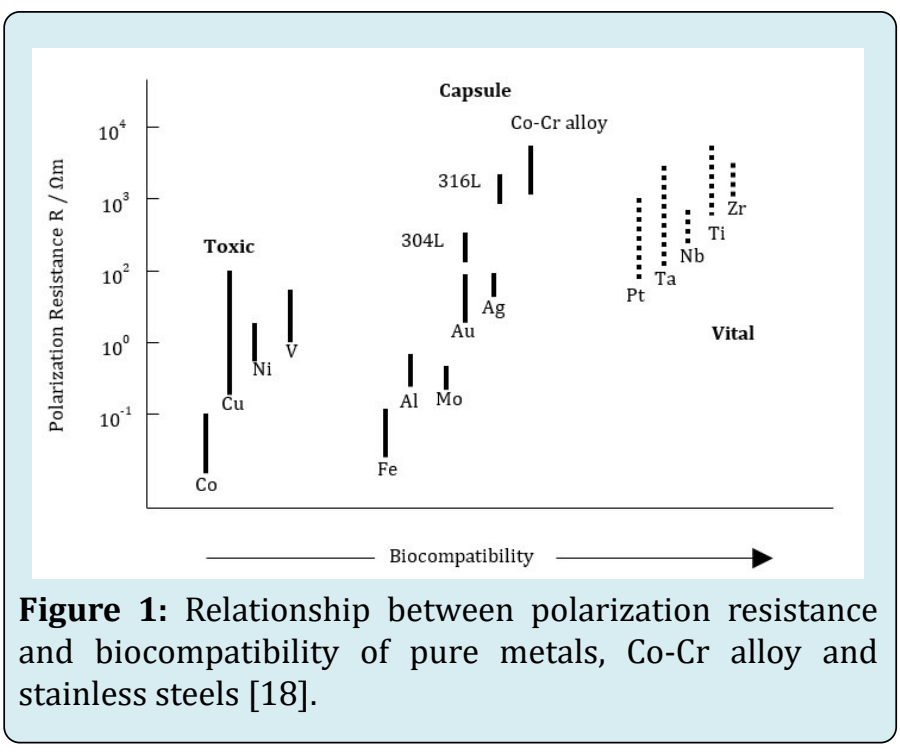

The negative issues caused by the mostly preferred $\mathrm{Ti}$ alloys in the body have paved the way for the development of $\beta$-type Ti alloys. $\beta$-stabilizing elements ( $\mathrm{Ta}, \mathrm{Nb}, \mathrm{Zr}, \mathrm{Mo}$ ) added to the alloy composition to maintain the $\beta$ phase in the structure has a low cytotoxic feature, and they exhibit excellent biocompatibility [13]. Besides, studies conducted on the alloying of $\mathrm{Nb}, \mathrm{Zr}$, and $\mathrm{Ta}$ elements with $\mathrm{Ti}$ reveal that the oxide layer formed on the Ti surface increases the thermodynamic stability. $\mathrm{Nb}_{2} \mathrm{O}_{5}, \mathrm{Ta}_{2} \mathrm{O}_{5}$, and $\mathrm{MoO}_{3}$ protective oxide layers in addition to $\mathrm{TiO}_{2}$, which is formed on the $\mathrm{Ti}$ surface, improve the structural integrity of the oxide layer by strengthening the $\mathrm{TiO}_{2}$ layer [22]. The alloying elements of $\beta$-type Ti alloys produced to be used in corrosive and aggressive body fluid do not pose any toxic hazard to the host organism compared to the materials preferred in implant production. This feature indicates that these alloys improve the biocompatibility properties of Ti-based materials.

\section{Conclusion}

Thanks to its body-centred cubic structure, $\beta$-type titanium alloys have a low modulus of elasticity and contain highly biocompatible alloy elements that without toxic effects. These features are the main characteristics that distinguish these materials from conventional materials used in implant production. Since the alloying elements are safe for the body and the material is developed taking into account biomechanical compatibility, it seems like a creative and innovative solution to two frequently encountered problems. In addition to these advantages, excellent forgeability in sheet form, hot-cold formability, and high fracture toughness characteristics of $\beta$-type $\mathrm{Ti}$ alloys constitute the reason for preferring $\beta$-type titanium alloys, particularly in the biomedical field, compared to Ti alloys with near- $\alpha$ and $\alpha+\beta$ phase structure.

\section{References}

1. Kumar A, Jayakumar T, Raj B, Banerjee D (2008) A new methodology for identification of $\beta$-transus temperature in $\alpha+\beta$ and $\beta$ titanium alloys using ultrasonic velocity measurement. Philos Mag 88(3): 327-338.

2. Yamanoglu R (2020) Network distribution of molybdenum among pure titanium powders for enhanced wear properties. Met Powder Rep.

3. Yang YL, Wang WQ Li FL, Li WQ Zhang YQ (2009) The Effect of Aluminum Equivalent and Molybdenum Equivalent on the Mechanical Properties of High Strength and High Toughness Titanium Alloys. Mater. Sci. Forum 618: 169-172.

4. Niinomi M, Nakai M (2011) Titanium-Based Biomaterials for Preventing Stress Shielding between Implant Devices and Bone. Int J Biomater 2011: 10.

5. Arifin A, Sulong AB, Muhamad N, Syarif J, Ramli MI (2014) Material processing of hydroxyapatite and titanium alloy (HA/Ti) composite as implant materials using powder metallurgy: a review. Mater Des 55: 165-175.

6. Sidambe AT (2014) Biocompatibility of advanced manufactured titanium implants - A review. Materials 7(12): 8168-8188.

7. Minagar S, Berndt CC, Wang J, Ivanova E, Wen C (2012) A review of the application of anodization for the fabrication of nanotubes on metal implant surfaces. Acta Biomater 8(8): 2875-2888.

8. Zhou Y-L, Niinomi M (2008) Microstructures and mechanical properties of Ti-50 mass\% Ta alloy for biomedical applications. J Alloys Compd 466(1-2): 535542 .

9. Niinomi M (1998) Mechanical properties of biomedical titanium alloys. Mater Sci Eng A 243(1-2): 231-236.

10. Wang K (1996) The use of titanium for medical applications in the USA. Mater Sci Eng A 213(1-2): 134137.

11. Davis JR (2003) Handbook of materials for medical devices: ASM International, Materials Park campus, Russell Township, Geauga, pp: 315.

12. Gepreel MA H, Niinomi M (2013) Biocompatibility of Tialloys for long-term implantation. J Mech Behav Biomed Mater 20: 407-415.

13. Wang K (1993) The Characterization of Ti-12Mo-6Zr2Fe A New Biocompatible Titanium Alloy Developed for 
Surgical Implant. Beta Titanium Alloys in the 1990's, pp: 49-60.

14. Zhang LC, Chen LY (2019) A review on biomedical titanium alloys: recent progress and prospect. Adv Eng Mater 21(4): 1801215.

15. Zhang L, Klemm D, Eckert J, Hao Y, Sercombe T (2011) Manufacture by selective laser melting and mechanical behavior of a biomedical Ti-24Nb-4Zr-8Sn alloy. Scr Mater 65(1): 21-24.

16. Hanawa T (2004) Metal ion release from metal implants. Mater Sci Eng C 24(6-8): 745-752.

17. Kuroda D, Niinomi M, Morinaga M, Kato $Y$, Yashiro $T$ (1998) Design and mechanical properties of new $\beta$ type titanium alloys for implant materials. Mater. Sci Eng A
243(1-2): 244-249.

18. Yamanoglu R, Efendi E, Daoud I (2017) Sintering Properties of Mechanically Alloyed Ti-5Al-2.5 Fe. Int J Eng 11(5): 360-364.

19. Yu J, Zhao Z, Li L (1993) Corrosion fatigue resistances of surgical implant stainless steels and titanium alloy. Corros Sci 35(1-4): 587-597.

20. Krewski D, Yokel RA, Nieboer E, Borchelt D, Cohen J, et al. (2007) Human health risk assessment for aluminium, aluminium oxide, and aluminium hydroxide. J Toxicol Environ Health Part B 10(S1): 1-269.

21. De Souza KA, Robin A (2003) Preparation and characterization of Ti-Ta alloys for application in corrosive media. Mater Lett 57(20): 3010-3016. 